\title{
The Heterogeneity of National Regulations in Clinical Psychology and Psychological Treatment in Europe
} Where Are We Coming From, Where Are We Now, and Where Are We Going?

\author{
Anton-Rupert Laireiter ${ }^{\mathrm{ab}}$, Cornelia Weise ${ }^{\mathrm{c}}$ \\ [a] Institute of Applied Psychology: Health, Development, Enhancement and Intervention, Faculty of Psychology, \\ University of Vienna, Vienna, Austria. [b] Division of Psychotherapy and Clinical Gerontopsychology, Department of \\ Psychology, University of Salzburg, Salzburg, Austria. [c] Division of Clinical Psychology and Psychotherapy, Department \\ of Psychology, Philipps-University of Marburg, Marburg, Germany.
}

Clinical Psychology in Europe, 2019, Vol. 1(1), Article e34406, https://doi.org/10.32872/cpe.v1i1.34406

Received: 2019-02-17 • Accepted: 2019-03-09 • Published (VoR): 2019-03-29

Handling Editor: Winfried Rief, Division of Clinical Psychology and Psychotherapy, Department of Psychology, Philipps-University of Marburg, Marburg, Germany

Corresponding Author: Anton-Rupert Laireiter, Faculty of Psychology, Liebiggasse 5, 1010 Vienna, Austria. Tel.: +43 (0)1 4277-47233; Mobil: +43 (0)664 432 3018. E-mail: anton-rupert.laireiter@univie.ac.at

\begin{abstract}
Background: The Bologna Process was initiated to harmonize study processes and contents throughout Europe in order to facilitate communication and cross-border study exchange. However, when it comes to postgraduate education and practical work in clinical psychology, no such harmonization exists - there is still significant heterogeneity between European countries.

Method: To initiate the section Politics and Education, we analysed the current situation in Europe with regard to national regulations on education, training and practice in clinical psychology and psychological treatment and give a brief summary on the status quo.

Results: There are extensive differences across Europe regarding governmental and national regulations for psychologists in general, and clinical psychologists in particular. Whereas some countries have very detailed regulations including a description of reserved activities for clinical psychologists, others leave the profession widely unregulated. When it comes to psychological treatment, some countries define it as an independent activity allowed to be applied by different professions, others clearly restrict access to the profession of psychotherapists.

Conclusion: A great diversity in national regulations and practical issues related to clinical psychology and psychological treatment exists across Europe. Our results underline the importance of the Politics and Education section in the journal Clinical Psychology in Europe in order to strengthen the development of an international perspective on clinical psychology.
\end{abstract}




\section{Keywords}

Clinical Psychology, psychological treatment, education, national regulations, Europe

\section{Highlights}

- National regulations for clinical psychologists differ significantly between European countries.

- Structure and contents of postgraduate training in clinical psychology vary widely across Europe.

- In some countries, treatment is reserved to psychologists, in others it's open for further professions.

- The Politics and Education section shall foster understanding, communication and cooperation.

The section "Politics and Education" has been included in Clinical Psychology in Europe (CPE) to inform our readers about national regulations for training and practice in clinical psychology and psychological treatment. To describe the current political and educational situation of clinical psychology in Europe, the Bologna Process is an important starting point: As an intergovernmental cooperation of 48 European countries, the Bologna Process aims to improve the internationalization of higher education throughout Europe. Its aim is to not only harmonize study processes and, in part, study contents across Europe, but also to facilitate an easier comparison of qualifications in order to facilitate exchange and cross-cultural communication. However, postgraduate education and practical work in various health professions have been unaffected by the Bologna Process (Baeten, 2017). This is of particular importance for clinical psychology, which is still a rather young and emerging profession. Currently, legal regulations for clinical psychologists (e.g. requirements for the admission to postgraduate training, structure and contents of postgraduate training, or prerequisites for work permission as a health care provider in a clinical practice) vary substantially throughout Europe (European Commission [EC], 2016; Hokkanen et al., 2019). Accordingly, clinical psychology in Europe is characterized by diversification rather than by convergence and agreement. Even neighboring countries, such as the Nordic countries or German-speaking ones, which in some cases cooperate very closely at university level, differ significantly in postgraduate education and their respective professional status (EC, 2016; Karayianni, 2018; Kryspin-Exner, Kothgassner, \& Felnhofer, 2017). Further substantial differences can be found in the relationship and differentiation between clinical psychology and psychological treatment (Van Broeck \& Lietaer, 2008).

Although the pan-European heterogeneity in clinical psychology is obvious, details about conditions in various countries are not well known. This applies both to countries and their bilateral communication, but also for multinational initiatives or the superordi- 
nate administration (e.g. the European Union, EU) (EC, 2016). Even professionals are often unaware of the regulations in their respective countries, not to mention the differences between countries. As a European journal of clinical psychology, it is an essential goal of CPE to shed light on this important issue.

The following article introduces this section of the journal and starts with an overview of different structures of governmental regulations for clinical psychology in Europe. In addition, we specify the tasks and objectives of this section and goals for possible contributions. We aim not only to provide information on differences between countries, but also to present strengths and limitations of various national regulations, and to provide examples that could be helpful for countries who are currently in the process of establishing national regulations for clinical psychology. Finally, knowledge about the heterogeneity of national regulations in clinical psychology is also essential for investigators of European projects including psychological treatments.

\section{Starting Points: Clinical Psychology in Academia and Clinical Practice}

Clinical psychology has different roots and traditions in Europe (Routh, 2014). Whereas more psychodynamically oriented approaches have been developed in Central Europe and influenced the German-speaking and Romano-phone countries, the empirically oriented Anglo-American tradition has had a substantial impact on the current state of clinical psychology in Europe (Routh, 2014). Although the understanding of clinical psychology as an empirical science with a strong neuro-scientific component has prevailed in academia in almost all European countries, the transfer of this conception into clinical practice varies widely (Cheshire \& Pilgrim, 2004; Plante, 2011). However, basic psychological and neuroscientific theories and empirical findings should be applied with the goal of improving the understanding as well as the classification, prevention and treatment of mental disorders and relevant psychological aspects of medical conditions. Instead, applied clinical psychology has been strongly influenced by the strong identification of psychologists, associations, and sometimes even societies with a specific approach to psychotherapy (e.g. psychodynamic, cognitive-behavioral, humanistic, or systemic approaches; Plante, 2011). It should be noted that this runs contrary to the primary goal of an academic profession: Practical work should not be based on selected belief systems, but on scientific evidence relevant to its field, along with clinical expertise.

\section{Governmental Regulations for Psychologists}

According to the EU, more than 6,000 professions are subject to state or supranational (EU) regulations, $42 \%$ of which are in the health and social care sector (Baeten, 2017). The 
professions of psychology and clinical psychology are, in most European countries, regulated by the relevant Member State, but are not subject to supranational EU regulations (EC, 2016). This adds to the understanding of the diversity of clinical psychology throughout Europe. Europe-wide analyses of the professional state of psychology and clinical psychology in the $28 \mathrm{EU}$ - and four of the non-EU states (i.e. Iceland, Liechtenstein, Norway and Switzerland) revealed the following picture (EC, 2016; Hokkanen et al., 2019): Only five states (15.6\%) had no legal or state regulation of any kind for psychology in general or health care in particular (EC, 2016, pp. 8ff.). Hokkanen et al. (2019) analyzed a slightly different sample and found state regulations in 25 out of 29 examined countries (86\%). Countries without any general psychology regulations are Bulgaria, Germany, and the three Baltic states, with Germany having regulations for psychological psychotherapists and child/adolescent psychotherapists, and Bulgaria stipulating minimal educational requirements for working as a psychologist in health care facilities. In 17 of the above mentioned 32 countries, there are regulations for the profession "psychologists" in general, some of which also include clinical-psychological activities. Twelve states have specific regulations for "clinical psychologists" and nine for "psychologists in health care" (health psychology). In 11 of these countries, there are separate regulations for other specialized psychologists and activities in various fields, for example forensic, counseling, school, traffic, occupational, or neuropsychologists (for further details see EC, 2016). In addition, some states have specific regulations for the treatment of children and adolescents (e.g. Czech Republic, Hungary, Lithuania and the United Kingdom [UK]). This brief overview clearly demonstrates how diversely the profession is regulated throughout Europe.

\section{Specific Regulations for Clinical Psychologists}

As reported above, 12 European countries have specific regulations for clinical psychologists, including Austria, Cyprus, the Czech Republic, Hungary, Iceland, Ireland, Malta, the Netherlands, Slovakia, Slovenia, Spain, and the UK (EC, 2016). Still, clinical psychologists are trained very differently; they have a differing range of reserved activities and work in diverse areas (e.g. public health care services vs. private sector). In some countries, clinical psychology is narrowly defined as a singular profession (e.g. Austria, Hungary and Czech Republic) whereas in others it is conceptualized as a clinically focused specialization of health psychology (e.g. Malta, Netherlands, Spain and the UK). In general, there is no consistent distinction between health psychology and clinical psychology: In some states, both professions are separated by their range of activities (e.g. prevention and health promotion vs. treatment and rehabilitation in Cyprus or the UK), in others by the severity of the mental disorder (e.g. health psychology for mild cases, and clinical psychology for severe cases in the Czech Republic or the Netherlands). Similarly, there are differing understandings of clinical psychology, clinical psychological treatment, and 
psychotherapy: In some countries, psychotherapy is a sub-specialization of clinical-psychology and thereby reserved for clinical psychologists (e.g. Slovakia, Hungary), in others, psychotherapy is a distinct profession with separate regulations and may also be open to holders of qualifications from related fields (e.g. medicine or pedagogy). As mentioned above, in some states clinical psychology is affiliated to other specialties, e.g. forensic psychology (Malta, Cyprus and the UK), neuropsychology (Netherlands and Hungary), or counseling psychology (Ireland, Malta, Slovakia, Czech Republic, UK and Cyprus) (see EC, 2016) which implies a specific appearance of clinical psychological work in these countries.

Differences across Europe are also evidenced by whether the title "Clinical Psychologist" is protected by a specific (psychology) law, or if the profession and its activities are only generally mentioned in another law, e.g. a health law. The former is the case in about $50 \%$ of European countries (Hokkanen et al., 2019), the latter in about one third (e.g. Denmark, Ireland and Spain). In some countries, both a title protection and a reference in specific health acts can be found (e.g. Iceland and Lithuania). Further differences pertain to the reservation of activities for clinical psychologists: According to the EC overview (EC, 2016, p. 19 ff.), two states have pure title protection without any reserved activities (Netherlands and the UK), three others have reserved activities without title protection (Ireland, Slovakia and Cyprus), and seven have both (Iceland, Malta, Austria, Slovenia, Spain, Czech Republic and Hungary).

And finally, the core competencies of clinical psychologists in Europe are defined to a differing degree. Competencies include in most European countries clinical-psychological diagnostics and assessment and psychological treatment. Additionally, clinical psychologists in various countries are enabled to carry out activities such as counseling, crisis intervention, education and training, as well as research and evaluation. In some countries these competencies are very clearly defined (e.g. Austria), in many others they are vaguely specified and are difficult to separate from activities of other professions in the health care system (EC, 2016).

\section{Education and Training in Clinical Psychology}

The situation of education and training for clinical psychologists is an important topic for the profession, and also for this journal. And again, there are tremendous differences between various European states regarding the structure, extent, and contents of training. In the majority of European countries, training in clinical psychology requires university studies (Bachelor and Master) followed by postgraduate training. Only in a few countries is training in clinical psychology already included during graduate studies (e.g. Norway). Postgraduate training varies between two to 12 years (EC, 2016) and contains a broad range of subjects, e.g. training in diagnostics and (clinical) psychological testing, training in counseling, specific treatment methods and crisis intervention as well as 
training in research methods and evaluation. In most curricula, specific obligatory courses are integrated into internships or trainee programs and are accompanied by continuous supervision. Moreover, in some countries the training is accompanied by personal and professional self-reflection (e.g. Austria), and is completed by a state examination (e.g. Austria or Spain) (EC, 2016). The most comprehensive training in clinical psychology can be found in the Czech Republic, Hungary, the Netherlands, Slovenia, and Spain (EC, 2016), where it is usually based on training in health psychology. Austria has the shortest training - of between 1.5 and 2 years.

\section{Differentiation Between Clinical Psychology and Psychological Treatment}

Significant differences between the European countries can also be found in the relationship between clinical psychology and psychological treatment (BPtK, 2011; EC, 2016; Van Broeck \& Lietaer, 2008). Of the 28 EU states, 13 separately regulate the profession of psychotherapists via governmental law (Austria, Belgium, Finland, France, Germany, Hungary, Italy, Lithuania, Luxembourg, the Netherlands, Romania, Slovakia and Sweden), a further three states regulate psychotherapists in a health-related law (Croatia, Latvia and Malta), and Bulgaria regulates the educational requirements for psychotherapists (Master's degree in psychology). Ireland and Cyprus are planning to issue laws for psychological treatment and two non-EU countries (Liechtenstein and Switzerland) already have them. However, the regulations of the different countries are very heterogeneous and differ significantly regarding their understanding of psychological treatment in general, criteria for theoretical and practical training, as well as the number of approved methods (Van Broeck \& Lietaer, 2008).

In Austria, Finland and Sweden, psychotherapy is defined as an independent occupation that can be learnt and practiced by different professions (almost 40 in Austria, eight to ten in Finland and Sweden). In most other countries, access to the profession of psychotherapists is restricted, mostly to psychologists and physicians/psychiatrists (e.g. France, Italy, Liechtenstein, Switzerland, Slovakia and Hungary). In Belgium, Germany and the Netherlands, pedagogues (general, clinical, or social pedagogues for children and adolescents) are additionally admitted to practice psychological treatment. Accordingly, in most European countries, non-medical psychological treatment is reserved to psychologists; in Hungary, psychotherapy is a reserved activity for clinical psychologists, an approach which is also planned in Ireland (EC, 2016).

In most countries, only the titles "psychotherapy" and "psychotherapist" are protected, but not the activity itself. Hence psychological treatment can also be carried out by other professions (e.g. physicians, clinical psychologists, and clinical pedagogues) in the context of their respective professional activities, although it is not permitted to be called 
"psychotherapy". In some countries, further specific activities (e.g. family therapy) are reserved for psychotherapists, (e.g. Germany, Hungary, Italy, Slovakia, and Switzerland).

There is also a great difference in the number of psychotherapeutic methods approved for training and practice. The numbers vary between four (Finland) and 23 (Austria), with five to seven approved methods in the majority of countries. The generally accepted methods are cognitive behavioral therapy (incl. 3rd wave methods), psychoanalysis, psychodynamically-oriented approaches (e.g. Analytic Psychotherapy following C.G. Jung, or Individual Psychology according to A. Adler), client centered psychotherapy according to Rogers, systemic (family) therapy, Gestalt therapy following Perls, existential psychotherapies (e.g. according to Frankl). Occasionally, hypnosis, integrative, or feminist therapies are also accepted (BPtK, 2011).

\section{Conclusion and Consequences}

In conclusion, we find a great diversity in regulations of clinical and health-related psychology and psychological treatment as well as in the relation of clinical psychology and psychological treatment on all levels of analysis. Psychological treatment is, in a few countries, reserved exclusively for clinical psychologists, whereas in others it can also be applied by other psychologists and/or other professions. In most cases, however, clinical psychology and psychological treatment are two independent professional fields. In Germany, for example, clinical psychology represents an academic-scientific subject and (psychological) psychotherapy is its application in practice (Kryspin-Exner et al., 2017). The great diversity and heterogeneity demonstrated in this overview underlines the importance of the goal of CPE's section "Politics and Education": Accomplishing transparency and clarity about the political and educational situation regarding clinical psychology and psychological treatment in Europe. This will be a necessary precondition for improving communication between different countries and different professions, for improving the field of clinical psychology as a whole, as well as for being able to coordinate European or multinational initiatives regarding research, structural changes, and psychological treatment.

\section{Tasks and Objectives of the "Politics and Education" Section}

It is the aim of the journal Clinical Psychology in Europe and its various sections to develop and strengthen an international perspective on clinical psychology and psychological treatment (https://cpe.psychopen.eu/about\#AimsandScope). Accordingly, for the section "Politics and Education", the main purpose is to publish articles dealing with various aspects of the political and legal situation and recent developments in Europe regarding training in clinical psychology and clinical psychological practice. The primary goal is to increase knowledge about different regulations and training modalities in Europe in or- 
der to foster understanding, communication and cooperation between professionals in the field of clinical psychology.

A central topic of European integration is promoting mobility and exchange of professions, which also applies for clinical psychology. On the one hand, clinical psychologists planning to move to another EU country or a country outside the EU should be kept fully informed about regulations as well as opportunities to perform their job in the respective country. On the other hand, comprehensive information is important for crossnational initiatives (e.g. on education and training in clinical psychology and psychological treatment), scientific projects, and the promotion of evidence-based practical applications of clinical psychology. It is, however, not planned to compile a legal encyclopedia in this section. Rather, papers should deal with the topics of interest in an introductory manner, provide an overview, and refer to further readings.

\section{Papers to Be Submitted to This Section}

Manuscripts submitted to this section should address one of the following topics: (1) legal regulations on education, training, and practice in clinical psychology and psychological treatment in health care; (2) specific aspects related to politics and education, e.g. prerequisites for, and contents of, training in various psychological treatments, or the relationship between clinical psychology and psychological treatment in a certain country; (3) commentaries on university studies (e.g. Master's or Doctorate level), European harmonization, or pan-European regulations (e.g. by the European Federation of Psychologists' Associations or other organizations) are also welcome. The focus of the papers should be on clinical psychology, or on psychological treatment as an area of the application of clinical psychology.

All contributions will be reviewed by the editors and must meet the requirements of the journal (for details please see https://cpe.psychopen.eu/about\#Author-Guidelines). Manuscripts should not exceed a maximum of 2,500 words (excluding references, author description and cover page). Papers can be submitted to the journal at any time. However, one of the editors should be contacted beforehand to agree upon the planned topic. In addition, the editors will actively invite experts to submit manuscripts on various topics of interest.

Funding: The authors have no funding to report.

Competing Interests: ARL is section editor of the Politics and Education section but played no editorial role for this particular paper. CW is Managing Editor of Clinical Psychology in Europe (CPE) but played no editorial role for this particular paper. The current paper was peer-reviewed by Winfried Rief, who is Editor-in-Chief of CPE.

Acknowledgments: The authors have no support to report. 


\section{References}

Baeten, R. (2017). Was the exclusion of health care from the Services Directive a pyrrhic victory? A proportionality test on regulation of health professions (OSE Paper Series, Opinion Paper No. 18, European Social Observatory). Retrieved from http://www.ose.be/files/publication/OSEPaperSeries/Baeten_2017_OpinionPaper18.pdf

Bundespsychotherapeutenkammer (BPtK). (2011). Psychotherapy in Europe - Disease management strategies for depression: National concepts of psychotherapeutic care. Retrieved from https://www.bptk.de/fileadmin/user_upload/Themen/PT_in_Europa/

20110223_nationalconcepts-of-psychoth-care.pdf

Cheshire, K., \& Pilgrim, D. (2004). A short introduction to clinical psychology. London, United Kingdom: Sage.

European Commission (EC). (2016). Mutual evaluation of regulated professions - Overview of the regulatory framework in the health services sector - Psychologists and related professions (Report GROW/E5). Retrieved from https://ec.europa.eu/docsroom/documents/16683?locale=en

Hokkanen, L., Lettner, S., Barbosa, F., Constantinou, M., Harper, L., Kasten, E., . . Hessen, E. (2019). Training models and status of clinical neuropsychologists in Europe: Results of a survey on 30 countries. The Clinical Neuropsychologist, 33(1), 32-56.

https://doi.org/10.1080/13854046.2018.1484169

Karayianni, E. (2018). A European perspective on regulating psychology: A review of the European Commission's mutual evaluation of regulated professions. Psichologija, 58, 125-134. https://doi.org/10.15388/Psichol.2018.7

Kryspin-Exner, I., Kothgassner, O. D., \& Felnhofer, A. (2017). Central Europe. In S. G. Hofmann (Ed.), International perspectives on psychotherapy (pp. 87-106). Cham, Switzerland: Springer. https://doi.org/https://doi.org/10.1007/978-3-319-56194-3

Plante, T. (2011). Contemporary clinical psychology (3rd ed.). Hoboken, NJ, USA: John Wiley \& Sons. Routh, D. K. (2014). A history of clinical psychology. In D. Barlow (Ed.), The Oxford handbook of clinical psychology (2nd ed., pp. 23-33). New York, NY, USA: Oxford University Press. https://doi.org/https://doi.org/10.1093/oxfordhb/9780195366884.001.0001

Van Broeck, N., \& Lietaer, G. (2008). Psychology and psychotherapy in health care: A review of legal regulations in 17 European countries. European Psychologist, 13(1), 53-63. https://doi.org/10.1027/1016-9040.13.1.53 